\title{
A 3-Phase 12/10 Asymmetrical Switched Reluctance Motor
}

\author{
M.T. Khor and R. Sotudeh \\ UNIVERSITY OF HERTFORDSHIRE \\ School of Electronic, Communication and Electrical Engineering \\ Hatfield, Hertfordshire, AL10 9AB, UK \\ Phone: +44 (0)1707 286279 Fax: +44 (0)1707 284199 \\ E-mail: m.t.khor@herts.ac.uk
}

\section{Keywords}

Switched reluctance motor, short flux path, finite element analysis

\begin{abstract}
This paper presents the design and operation of a switched reluctance motor (SRM). The designed motor is a 3-phase 12/10 irregular structured type which only operates in short flux path instead of classical long flux path. Switched reluctance motor has very high nonlinear magnetisation characteristics. Finite element analysis (FEA) was used to obtain the nonlinear magnetisation data for application to the modelling. Analyses and verifications obtained from simulation and modelling were used as a guide to design the SRM.
\end{abstract}

\section{Introduction}

Switched reluctance motor (SRM) is attracting interest due to its simple construction, low manufacturing cost, reliable operation and high efficiency. It has a high power to weight ratio and robust rotor structure which is capable of operating in harsh environments [1], [7]. Recent advances in power electronics and microelectronics have demonstrated the huge potential of switched reluctance motor drives. The manufacturing and maintenance costs for switched reluctance motor drives will be much lower than alternatives such as the brushless DC motor, the induction motor and the AC motor [1].

A prototype 3-phase 12/10 irregular switched reluctance motor has been designed. This motor has irregular stator geometry as shown in Fig. 1 and Fig. 2. The motor is operated in short flux path instead of long flux path due to the irregular structure on the stator and the connection of its phase winding. The purpose of this paper is to present the design of this motor using a short flux path technique. The magnetic flux of this designed switched reluctance motor flows in a shorter loop in adjacent pole-pairs compared to conventional switched reluctance motors in which the flux flows in a long flux path.

\section{Basic Principles of SRM}

The switched reluctance motor is a doubly-salient and singly-excited motor. The torque is produced by the tendency of its moveable part to move to the position where the inductance of the excited phase winding is minimised. The magnetic flux of the designed switched reluctance motor flows in a shorter loop in adjacent pole-pairs. The two loops are shown in Fig. 4 is the short flux paths of the excited phase. The arrows show the direction of the electromagnetic flux. 


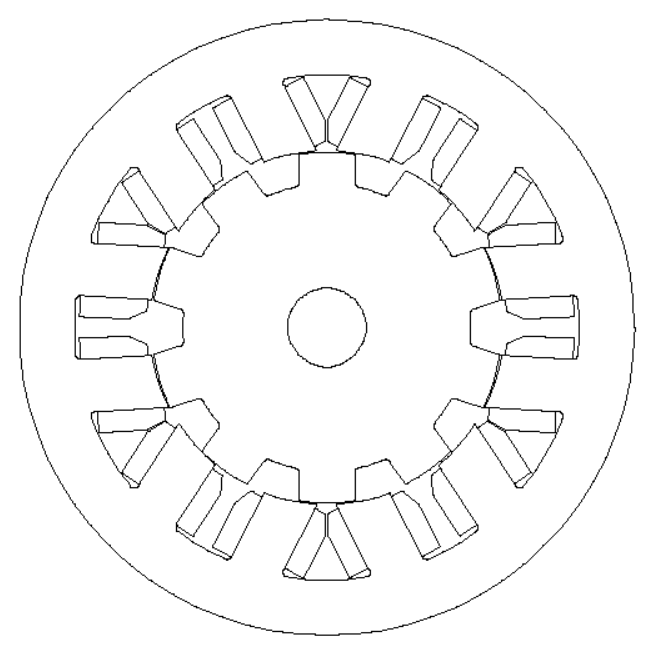

Fig. 1: Aligned position for phase 1

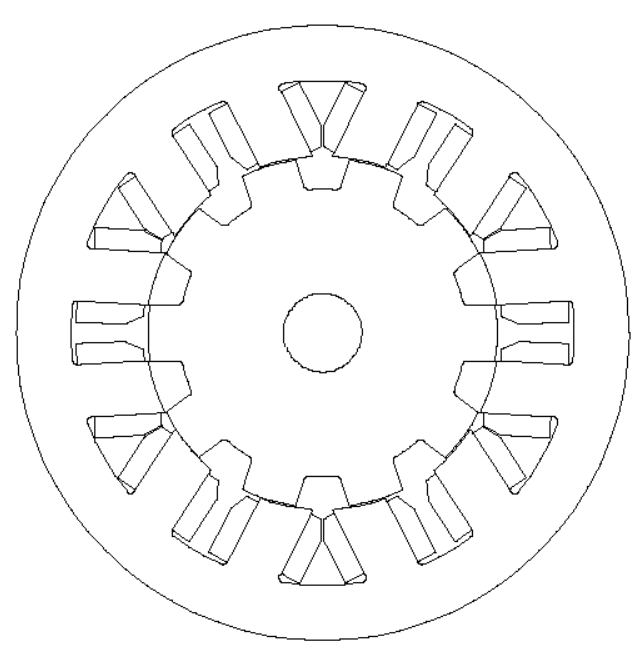

Fig. 2: Unaligned position for phase 1

\section{Electromagnetic Analysis}

Finite element analysis (FEA) is an interactive software package which is used to solve 2D and 3D static magnetic field problems. The software includes features for geometry input, finite element mesh generation, pre-processing and post-processing functions. Accurate data for a prototype switched reluctance motor can be obtained from finite element analysis's simulation and modeling.

FEA is used to obtain the nonlinear magnetization data for application to the modelling [2]. The mathematical model of the SRM is based on the flux linkage equation which is defined as

$$
\lambda=\int(v-R i) d i
$$

where $\lambda$ - phase flux linkage, $\mathrm{Wb}$

$v$ - phase voltage, $\mathrm{V}$

$R$ - phase resistance, $\boldsymbol{\Omega}$

$i$ - phase current, A

From equation (1), gives the voltage equation for the designed SRM as:

$$
\begin{gathered}
v_{m}=R_{m} \cdot i_{m}+\frac{d \lambda_{m}}{d t} \\
m=a, b, c \\
\lambda_{a}=L_{a a} \cdot i_{a}+L_{a b} \cdot i_{b}+L_{a c} \cdot i_{c} \\
\lambda_{b}=L_{a b b} \cdot i_{a}+L_{b b} \cdot i_{b}+L_{b c} \cdot i_{c} \\
\lambda_{c}=L_{a c} \cdot i_{a}+L_{b c} \cdot i_{b}+L_{c c} \cdot i_{c}
\end{gathered}
$$

$L_{a c}, L_{b b}, L_{c c}$ : self inductances

$L_{a b}, L_{b \infty}, L_{a c}$ : mutual inductances 
Due to the irregular 12/10 SRM topology, the mutual inductances are extremely small compared to classical SRM. Hence, the mutual inductances can be neglected in this case. The voltage equation can be rewritten as,

$$
\begin{aligned}
& \lambda_{a}=L_{a a} \cdot i_{a t} \\
& \lambda_{a}=L_{b b} \cdot i_{b} \\
& \lambda_{c}=L_{c c} \cdot i_{c}
\end{aligned}
$$

For simplicity,

$$
\lambda_{m}=L_{m} \cdot i_{m}
$$

$m=a, b, c$

The flux linkage of the switched reluctance motor is a function of current and rotor position, therefore the voltage equation can be rewritten as:

$$
\begin{aligned}
v_{m t} & =R_{n t} \cdot i_{n t}+\frac{d}{d t}\left(L_{m} \cdot i_{m}\right) \\
& =R_{m} \cdot i_{m}+L_{m} \frac{d i_{m}}{d t}+i_{m} \cdot \frac{d L_{m}}{d \theta} \omega
\end{aligned}
$$

where

$$
\begin{aligned}
& \mathrm{m}=\mathrm{a}, \mathrm{b}, \mathrm{c} \\
& \theta \text { is the rotor angle } \\
& \omega \text { is the angular speed }
\end{aligned}
$$

The static torque of the SRM can be calculated by using the virtual work method, applying partial derivative of the co-energy with respect to rotor displacement under constant current. Co-energy, $W_{c e}$ is the energy conversion of the nonlinear electromechanical system.

$$
\begin{aligned}
& W_{c e}=\left.\int \lambda d i\right|_{\theta=\text { constant }} \\
& T(\theta, i)=\left.\frac{\partial W_{c e}}{\hat{\partial} \theta}\right|_{i=\text { constant }}
\end{aligned}
$$

where $T$ - static torque, $\mathrm{Nm}$

$$
\begin{aligned}
& W_{c e} \text { - co-energy, J } \\
& \theta \text { - rotor position, mechanical degree } \\
& i \quad \text { - stator current, A }
\end{aligned}
$$

The FE mesh generated from the FEA software has shown in the Fig. 3. A detail of the finite element mesh with 9082 elements was used to analyze the prototype SRM. The mesh was refined in regions such as air gaps, stator and rotor pole tips where the flux density was relatively high. 


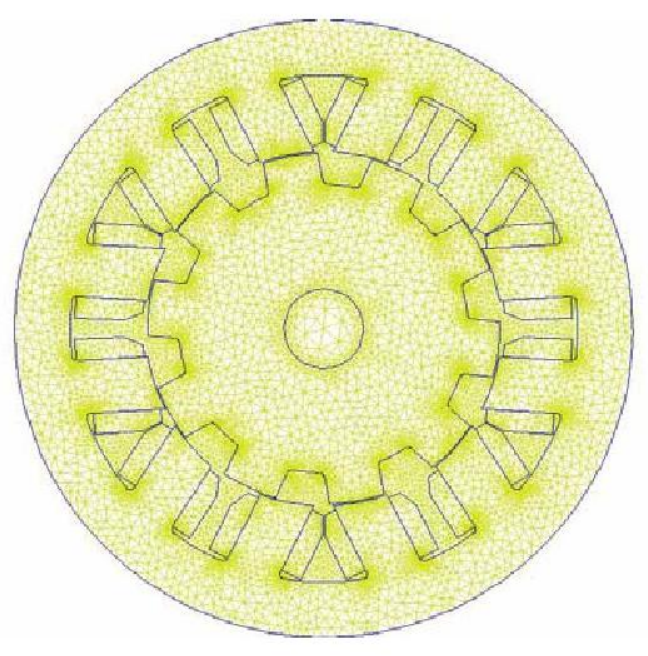

Fig. 3: Finite element mesh of the designed SRM

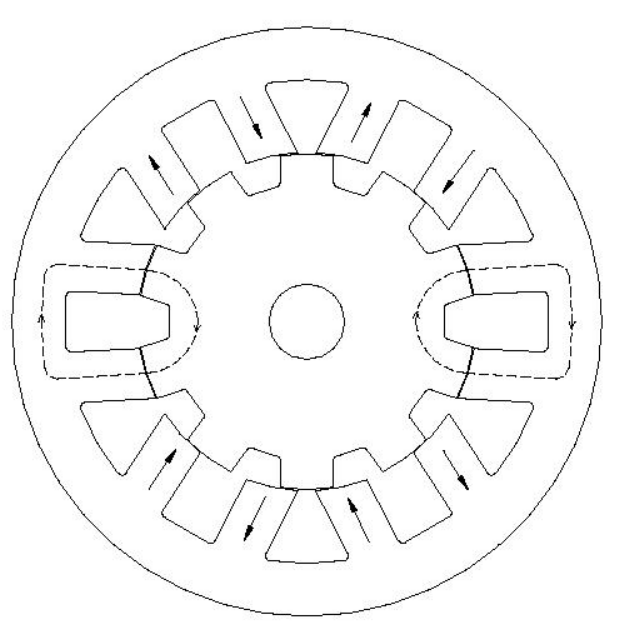

Fig. 4: Short flux path excitation of a $12 / 10$ SRM

\section{Short Flux Path}

The electromagnetic operation for the designed SRM is different from that of a conventional SRM. Magnetic flux travels in a short flux loop in contrast to conventional SRMs which use a long flux loop.

Fig. 4 depicts the flux distribution for Phase 1 with rotor at 0 degree. When a stator pole-pair is excited the most adjacent rotor pole-pair is attracted towards the excited stator pole which will achieve alignment between both stator poles and rotor poles. This is caused by the nature of the reluctance path [6]. Fig. 5 and Fig. 6 show a comparison between the long flux paths of the classical $6 / 4$ switched reluctance motor, and the $12 / 10$ short flux path switched reluctance motor. The 6/4 SRM is clearly shown with longer magnetic flux path. Fig. 7 shows one mechanical degree increment for the switched reluctance motor.

The advantages of using a short flux path are to reduce the eccentric forces between the stator and rotor poles. In addition, core losses are significantly reduced due to the short distance of the travelling magnetic fields in the short flux path design. Flux reversals in the back iron are also eliminated [1]. The disadvantage arises from the asymmetrical structure of the stator poles structure which limits the space available for the coil windings.

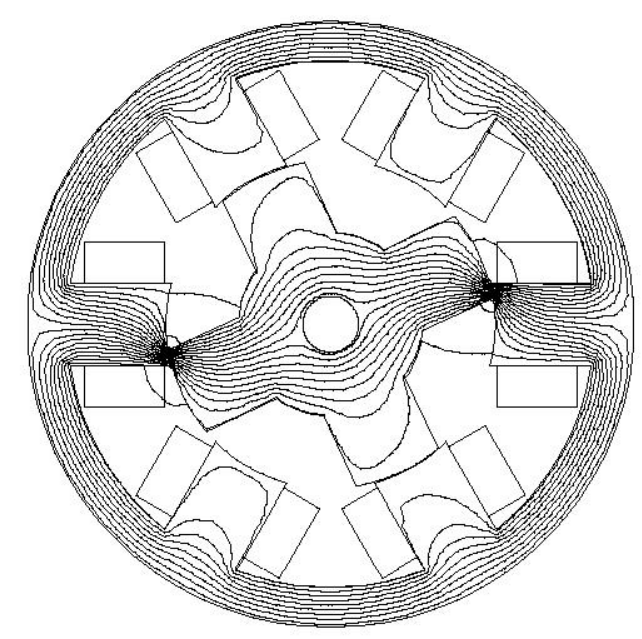

Fig. 5: Distribution of magnetic flux (long flux path) in the conventional $6 / 4$ poles switched reluctance motor

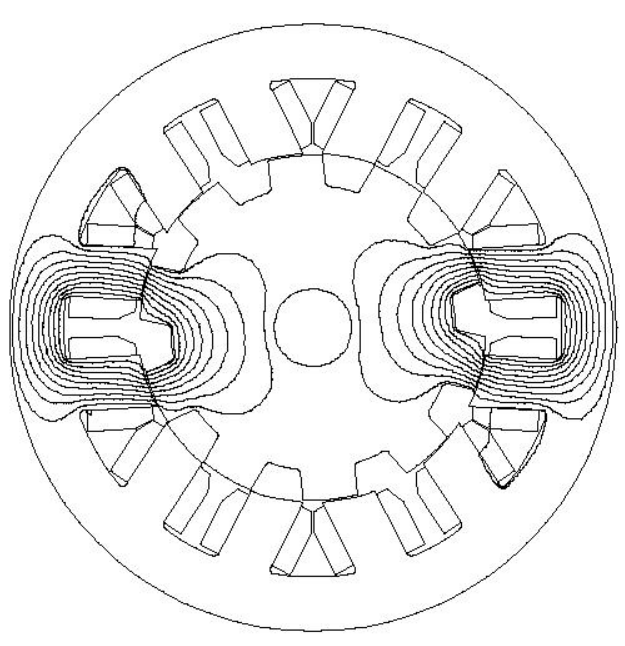

Fig. 6: Distribution of magnetic flux (short flux path) in the designed $12 / 10$ poles switched reluctance motor 

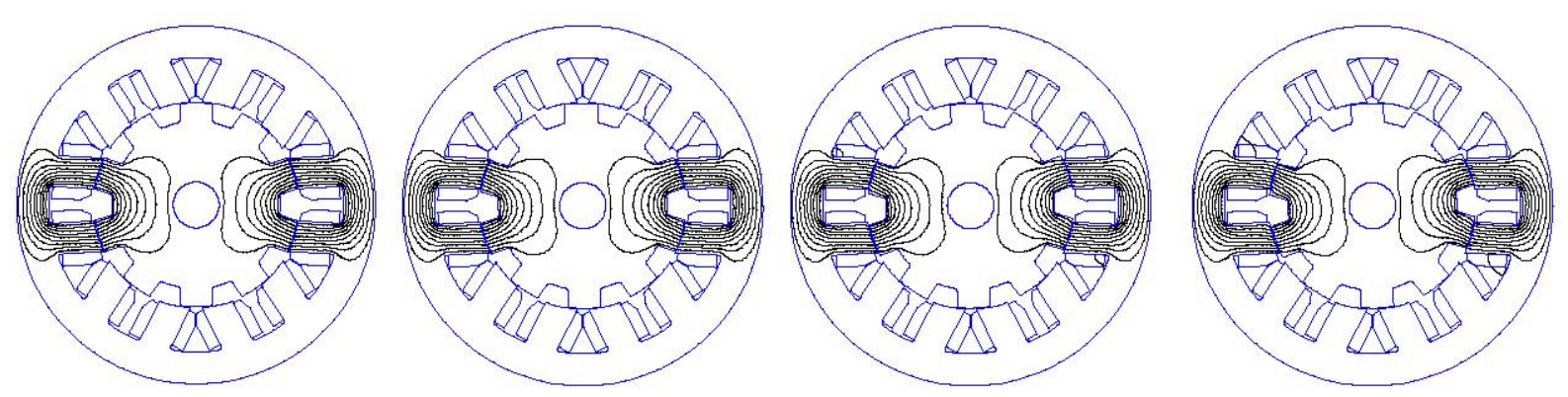

(a) 0 degree (cully-aligned)

(b) 1 degree

(c) 2 degrees

(d) 3 degrees

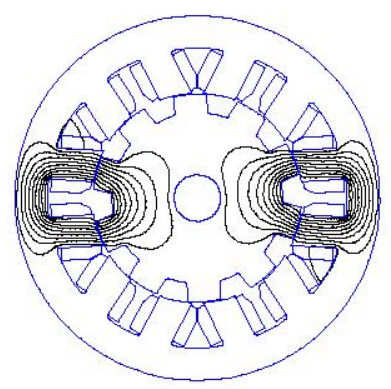

(e) 4 degrees

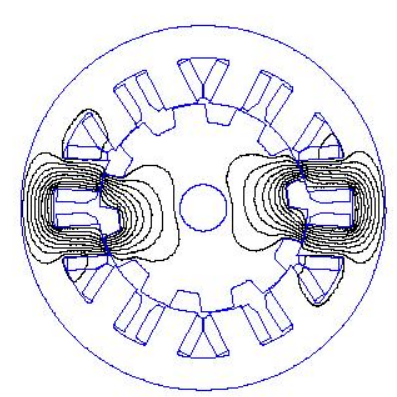

(i) 8 degrees

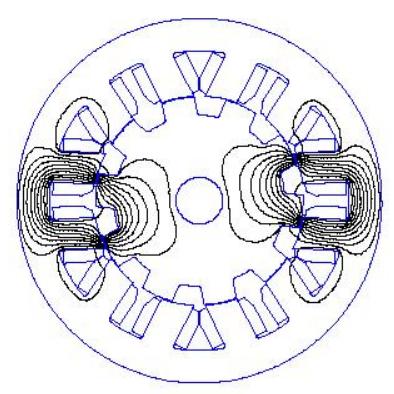

(m) 12 degrees

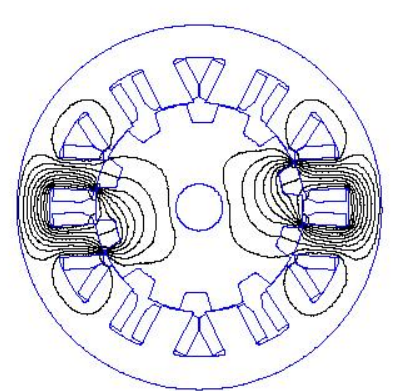

(q) 16 degrees

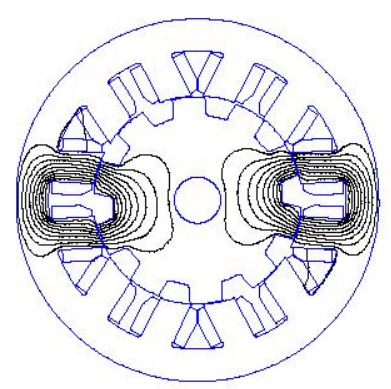

(f) 5 degrees

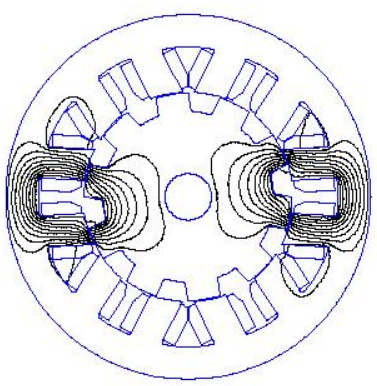

(j) 9 degrees

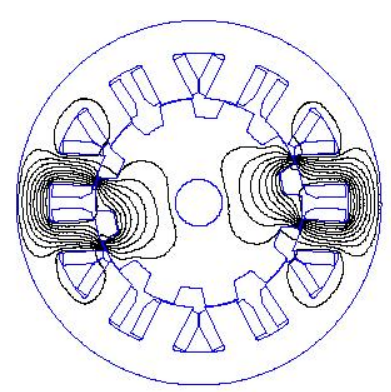

(n) 13 degrees

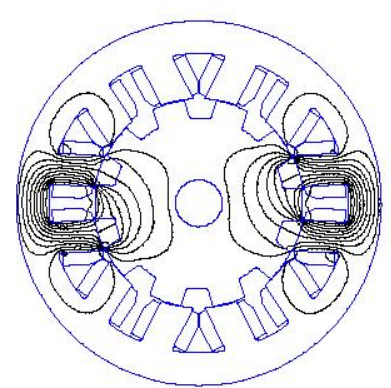

(r) 17 degrees

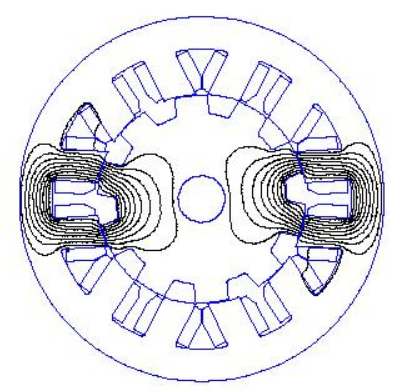

(g) 6 degrees

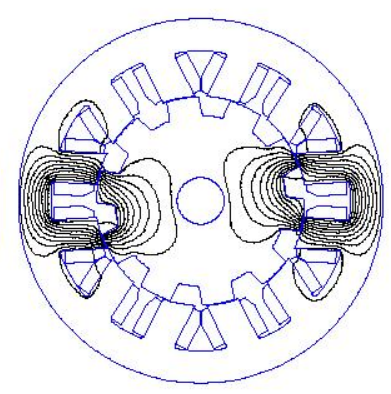

(k) 10 degrees

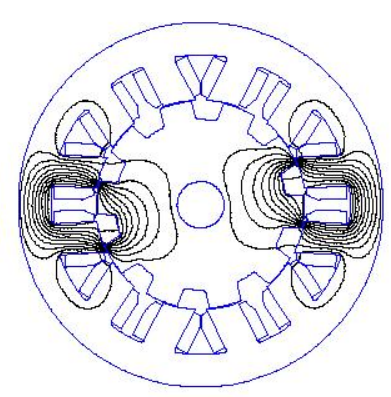

(o) 14 degrees

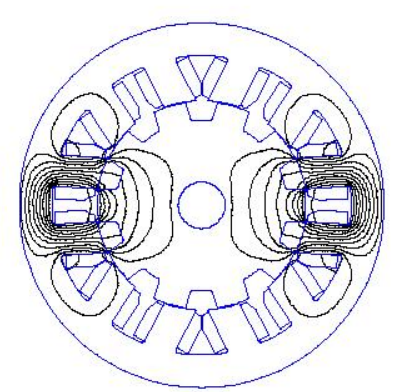

(s) 18 degrees (fully-unaligned)

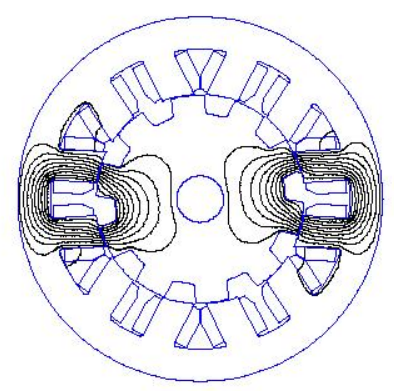

(h) 7 degrees

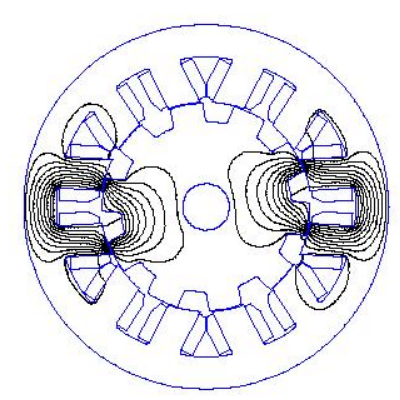

(1) 11 degrees

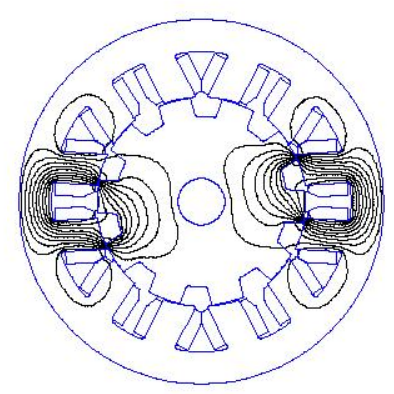

(p) 15 degrees

Fig. 7: Magnetic flux distributions at different angular positions of the switched reluctance motor 


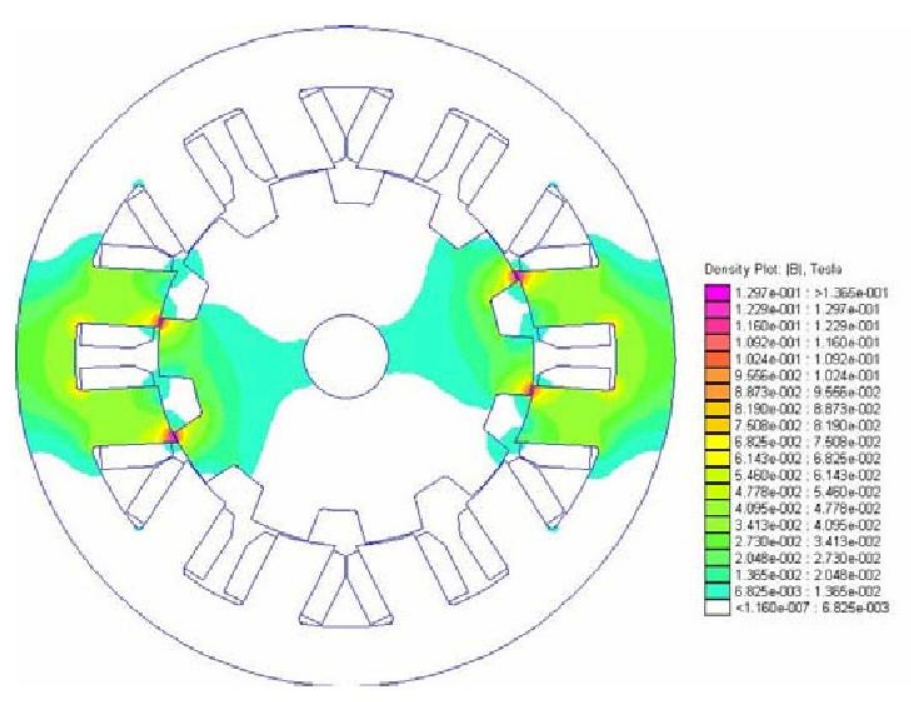

Fig, 8: Magnetic flux density plot of the switched reluctance motor when rotor pair-poles are overlapped with stator pair-poles

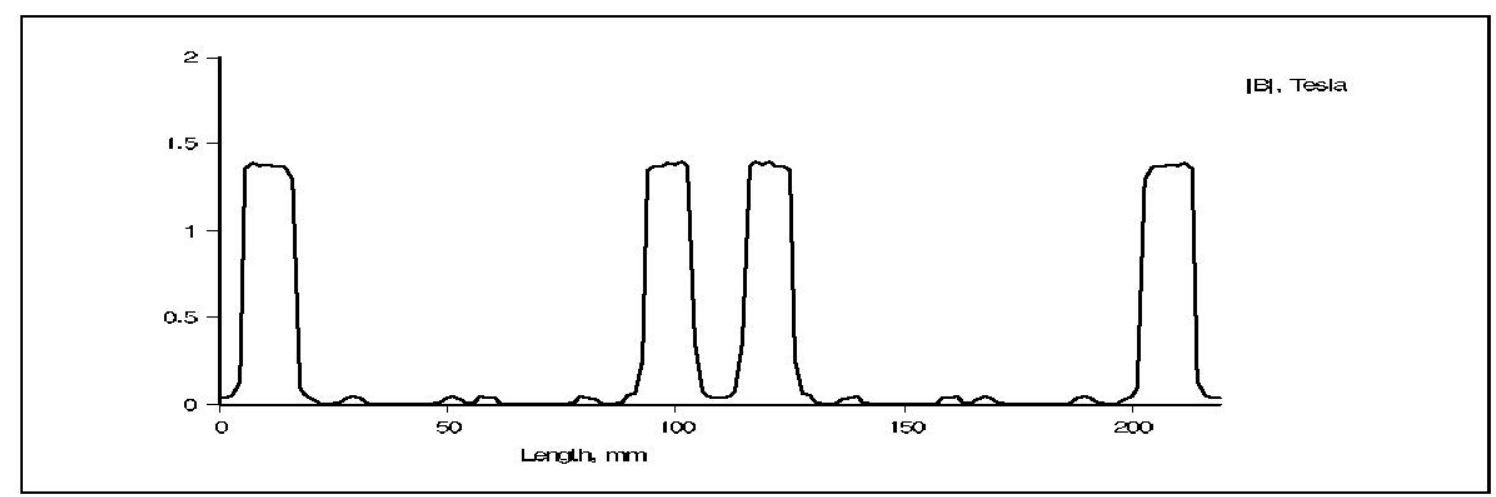

Fig. 9: Magnitude of flux density with respect to angular distance when phase 1 is excited $\left(\theta_{\mathrm{r}}=0^{\circ}, \mathrm{i}_{1}=15 \mathrm{~A}\right)$

A magnetic flux density plot of the designed switched reluctance motor is shown in Fig. 8. The flux density legend chart in the figure indicates that a high magnetic flux density of more than 1.5 Tesla was produced in the region when the stator and rotor poles start to overlap. There are very low magnetic flux densities produced apart from the excited pole-pair regions. The magnitude of flux density is shown in Fig. 9 which was obtained from a full revolution of the SRM for 360 degrees or $218.027 \mathrm{~mm}$ angular length. By injecting 15A current into the fully aligned SRM, magnetic flux density with average 1.4 Tesla is produced along the excited pole-pairs.

\section{Simulation, Modelling and Results}

Simulation and modelling of the 3-phase switched reluctance motor was implemented to investigate the motor dynamies. In order to analyze the dynamics of the switched reluctance motor, a mathematical model of the drive system must be created. The mathematical model was formed using the electromagnetic characteristics of the motor like flux-linkages, inductance, rotor position, current and torque profiles. The flux linkage characteristics of the SRM were analysed and calculated using CAD, FEA and MATLAB software. These results are important to the simulation and modelling of the SRM. Fig. 10 shows the flux linkage characteristics for the designed SRM versus rotor position at different current levels. In Fig. 11, $\theta_{a}$ is the aligned position when the rotor is stopped in 0 degree 
location and $\boldsymbol{\theta}_{\mathrm{u}}$ is unaligned position when the rotor is stopped in 18 degrees location of the switched reluctance motor. There are 1.5 degrees increments for each of the magnetisation curves shown in the figure. The magnetisation curve for the unaligned position is a linear line, whereas the aligned position has the most saturated line. Saturation happens when the rotor and stator poles start to overlap and when the motoring current has reached $2.5 \mathrm{~A}$ and above.

The static torque of the designed switched reluctance motor with $2 \mathrm{~A}, 4.5 \mathrm{~A}$ and $6 \mathrm{~A}$ phase current is shown in Fig. 12. This is the torque created during locked rotor conditions. Static torque must be measured while exciting one phase at fixed current for a rotor position. This can be obtained from hardware based experiments or mathematical analyses. Static torque is obtained from the magnetisation curves based on the concept of the virtual work principle and Maxwell stress tensor methodology [8]. When the phase current is turned-on at 6A, approximately $9 \mathrm{Nm}$ maximum torque is produced and when current is turned-on at $2 \mathrm{~A}$, only a $2 \mathrm{Nm}$ maximum torque is produced. The result of the static torque will be applied in the simulation and modelling of the switched reluctance motor.

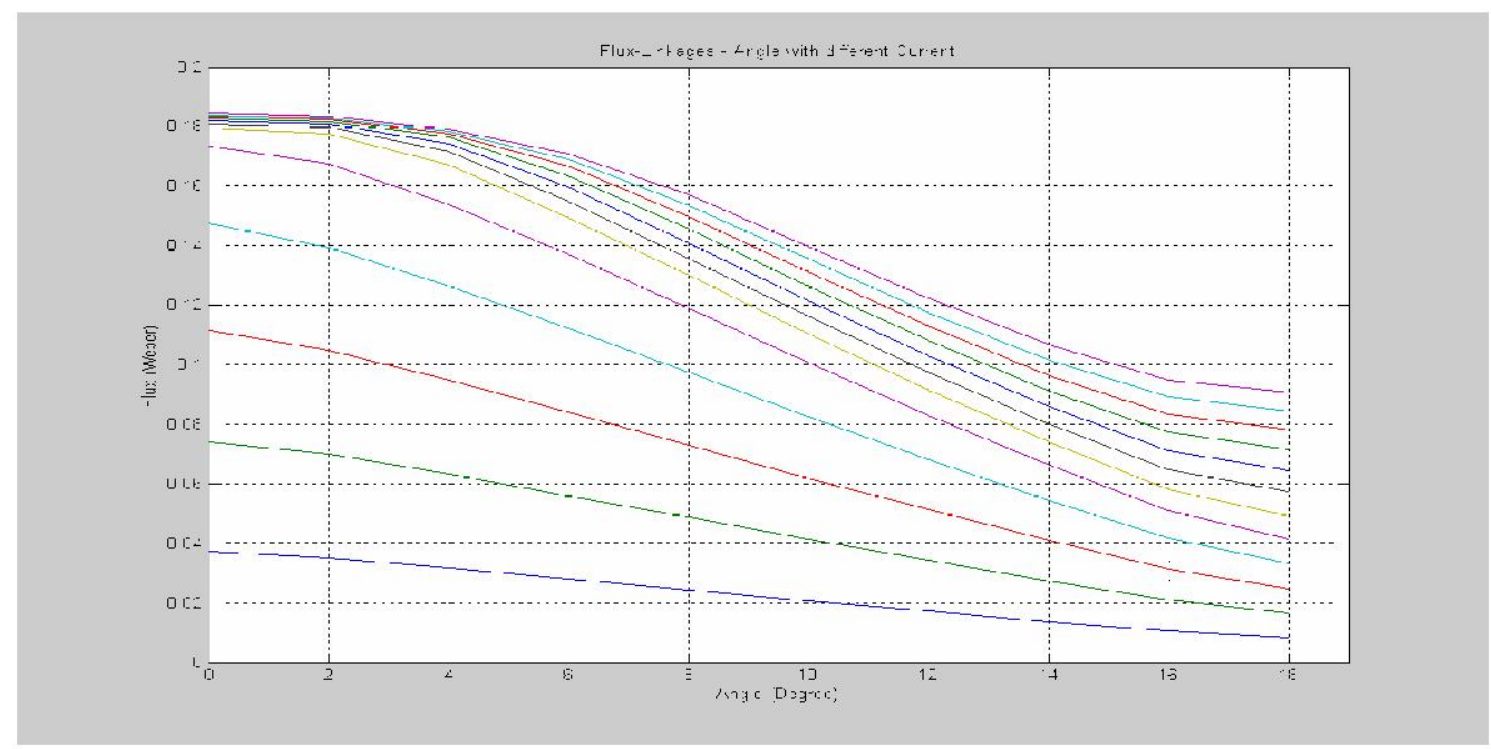

Fig. 10: Flux linkage versus rotor position at different current levels

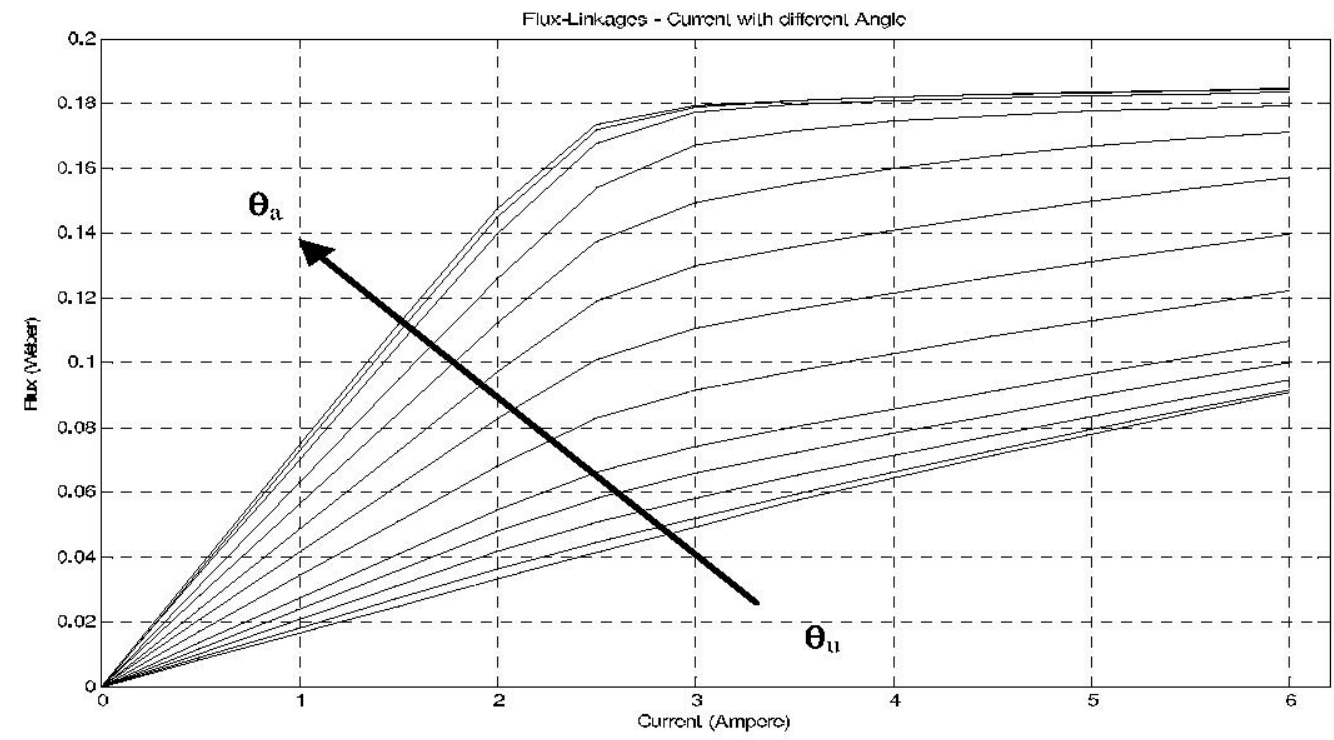

Fig. 11: Flux linkage profile at different current levels and rotor angles 


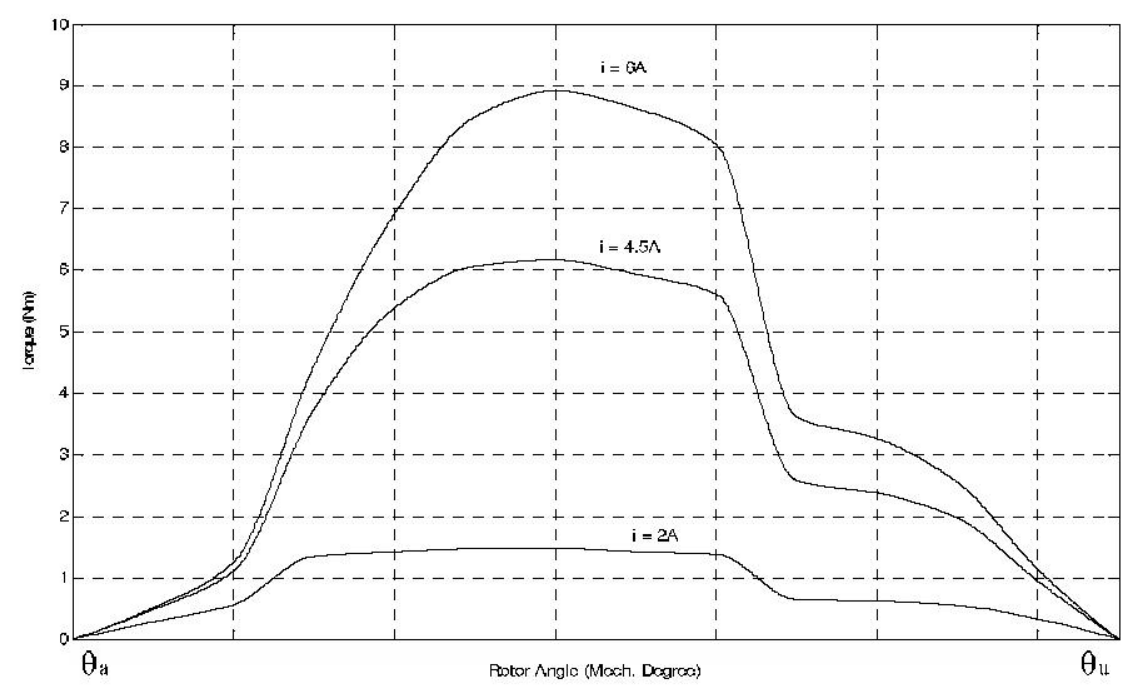

Fig. 12: Static torque of the SRM for single-phase excitation with $2 \mathrm{~A}, 4.5 \mathrm{~A}$ and $6 \mathrm{~A}$

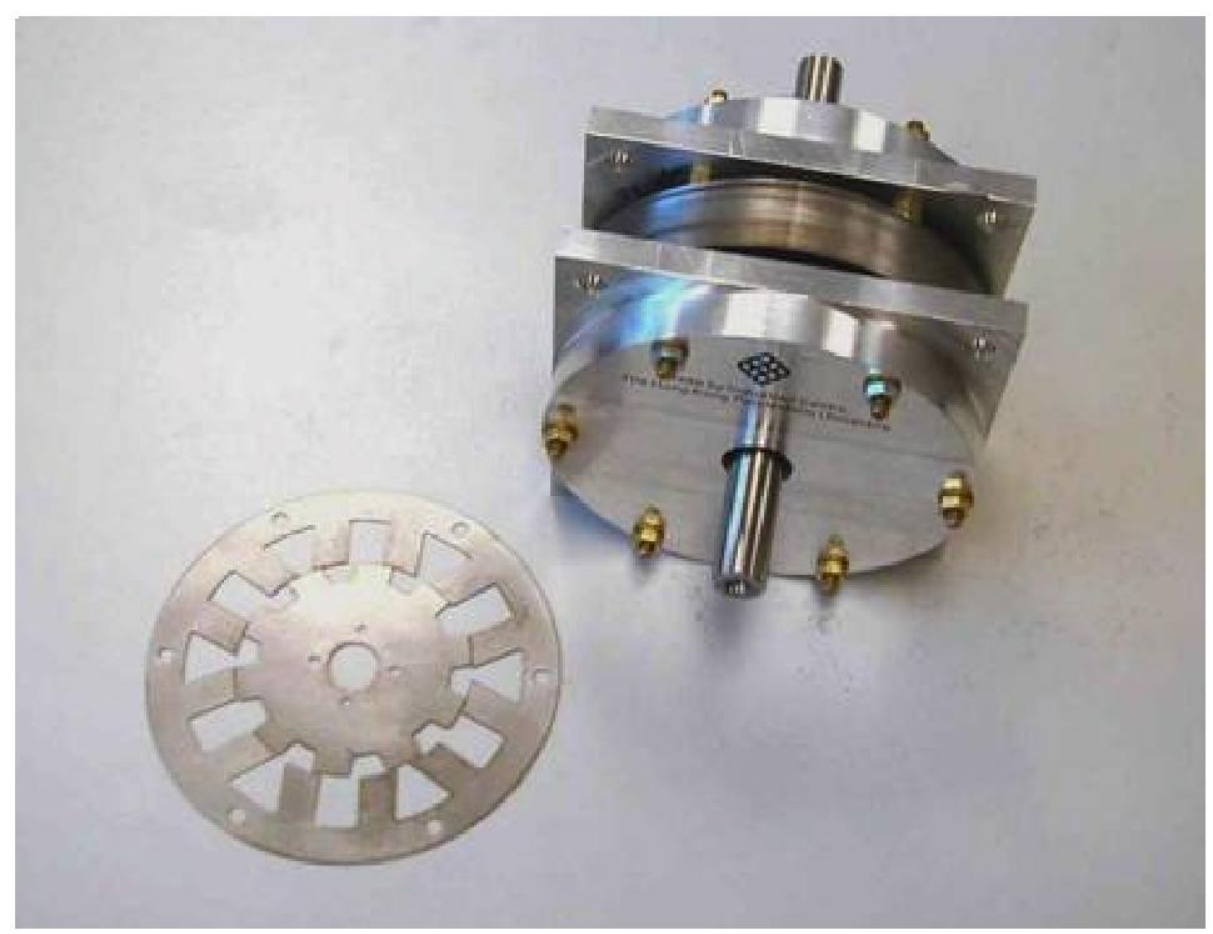

Fig. 13: 3-phase 12/10 SRM

\section{Conclusions and Future Work}

A 3-phase, 12/10 poles short flux path switched reluctance motor was analysed, designed and implemented. This motor has an irregular structure which is different to the classical switched reluctance motor. Simulation and modelling were conducted to obtain the electromagnetic characteristics of the switched reluctance motor based on short flux path magnetic distribution. Magnetisation curves and static torque parameters were analysed and obtained numerically using a finite element analysis approach. Finally, a prototype SRM was built based on the finite element analysis and analytical studies. Fig. 13 shows a photo of the prototype 3-phase 12/10 SRM. In the future, practical control experiments will be untaken to validate the prototype SRM design. 


\section{References}

[1]. T.J.E. Miller, "Switched Reluctance Motor and Their Control", Hillsboro, OH: Magna Physics and Oxford Clarendon Press, 1993.

[2]. T.J.E. Miller, M. Mcgilp, "Nonlinear theory of the switched reluctance motor for computer-aided design", IEE Proc. Pt. B, Vol. 137, No.6, Nov 1990.

[3]. Hendershot, J.R., "Short flux loops cool SR motors", Machine Design, pp.106-111, 1989.

[4]. A.M. Michaelides, C. Pollock, "Modelling and design of switched reluctance motors with two phases simultaneously excited", IEE Proc.-Electr Power Appl., Vol. 143, No.5, pp.361-370, 1996.

[5]. S. Wallace and D.G. Taylor, "A Balanced Commutator for Switched Reluctance Motors to reduce Torque Ripple", IEEE Transactions on Power Electronics, Vol. 7, No. 4, pp. 617-626, October 1992.

[6]. Krishnan, R.; Arumugam, R.; Lindsay J. F., "Design Procedure for Switched-Reluctance Motors", IEEE Trans. on Industry Applications, Vol. 24, No. 3, pp. 456-461, 1988.

[7]. Krishnan, R., "Switched Reluctance Motor Drives: Modeling, Simulation, Analysis, Design, and Applications", CRC Press, 2001.

[8]. H.H. Moghbelli, G.E. Adams and R.G. Hoft, "Prediction of the Instantaneous and Steady State Torque of the Switched Reluctance Motor Using the Finite Element Method (FEM), IEEE, 1998. 